\title{
Synovial Sarcoma Parotid Gland: Diagnostic Dilemma
}

\author{
${ }^{1}$ Arun Prabhu Ganeshan, ${ }^{2}$ Bennet Rajmohan, ${ }^{3} \mathrm{G}$ Amarnath, ${ }^{4}$ Vikas Jain
}

\begin{abstract}
Synovial sarcoma is a deep soft-tissue mesenchymal tumor, primarily arising in extremities. Rarely, does it present as a head and neck tumor, out of them very few reported cases are from parotid gland origin.

We report a case of synovial sarcoma of parotid gland in 20 -year-old female progressing in short duration. A review of literature is undertaken considering most of discretely reported cases in English literature and elaborates the pathological features that help to reach in diagnosis.

Review of literature suggests that synovial sarcoma of rare origins like parotid produces a diagnostic dilemma. Histological diagnosis is generally a late postoperative finding. Due to the rarity of this entity, few cases have been described in the literature and treatment is still not well codified. Clinical suspicion with molecular studies help to reach the accurate diagnosis which is mandatory for proper management as the treatment strategy is different from routine parotid tumors.
\end{abstract}

Keywords: Synovial sarcoma, Carcinoma, Parotid gland, Head and neck tumors, Orofacial, Spindle cell tumor.

How to cite this article: Ganeshan AP, Rajmohan B, Amarnath G, Jain V. Synovial Sarcoma Parotid Gland: Diagnostic Dilemma. Int J Head Neck Surg 2015;6(1):29-31.

Source of support: Nil

Conflict of interest: None

\section{INTRODUCTION}

Synovial sarcoma is a common mesenchymal tumor of deeper soft tissue in extremities, most commonly in lower thigh-knee region, basically derived from synovial lined spaces, but unusual and distant from synovial space sites are also described in literature, particularly the abdominal wall and head and neck region. ${ }^{1}$ Head, and neck SS have 3 to $10 \%^{2}$ of all SS, commonly in cervical and para-pharyngeal region and quite often the correlation with synovial structures remains unclear), because this region is poor in synovioblastic tissue. Very rarely, it appears in orofacial region and only countable few cases

\footnotetext{
${ }^{1-3}$ Consultant, ${ }^{4}$ Postgraduate

${ }^{1}$ Department of Head and Neck Surgery, Apollo Speciality Hospital, Madurai, Tamil Nadu, India

${ }^{2,4}$ Department of General Surgery, Apollo Speciality Hospital Madurai, Tamil Nadu, India

${ }^{3}$ Department of Raditation Oncology, Apollo Speciality Hospital Madurai, Tamil Nadu, India

Corresponding Author: Arun Prabhu Ganeshan, Consultant Department of Head and Neck Surgery, Apollo Speciality Hospital, Madurai, Tamil Nadu, India, Phone: 9842328842 e-mail: dr.arunprabhu@yahoo.com
}

are reported from parotid salivary gland origin. We here have presented a case report of such parotid synovial sarcoma with most rapid presentation in comparison to all previous cases reported.

\section{CASE REPORT}

A 26 years old female presented with progressively increasing swelling in right-parotid region for last 3 months. Occasionally, she was having pain during eating otherwise no other functional disturbances. No evidence of facial nerve weakness seen. On examination, swelling was firm, nontender and noninflamed, no palpable cervical lymph nodes (Fig. 1).

Ultrasonogram showed cystic swelling right superficial lobe of parotid.

Fine needle aspiration cytology (FNAC) done elsewhere showed monomorphic adenoma right parotid.

Computed tomography (CT) scan of the neck with IV contrast (Fig. 2) revealed well-defined rounded heterogeneously enhancing mass, $4 \times 3.4 \times 2.4 \mathrm{~cm}$, within anterior aspect of superficial lobe of right parotid.

\section{PLEOMORPHIC ADENOMA}

Also, another $13 \times 9.3 \mathrm{~mm}$ soft-tissue density anterior to main mass adherent to capsule of right parotid gland probably non-necrotic preparotid lymphadenopathy.

So, superficial parotidectomy was planned considering pleomorphic adenoma. Intraoperatively, we found a firm deep lobe tumor with minimal involvement of facial nerve (Fig. 3). So, total conservative parotidectomy done along with group of lymph node excision (Fig. 4) and sent for histopathology.

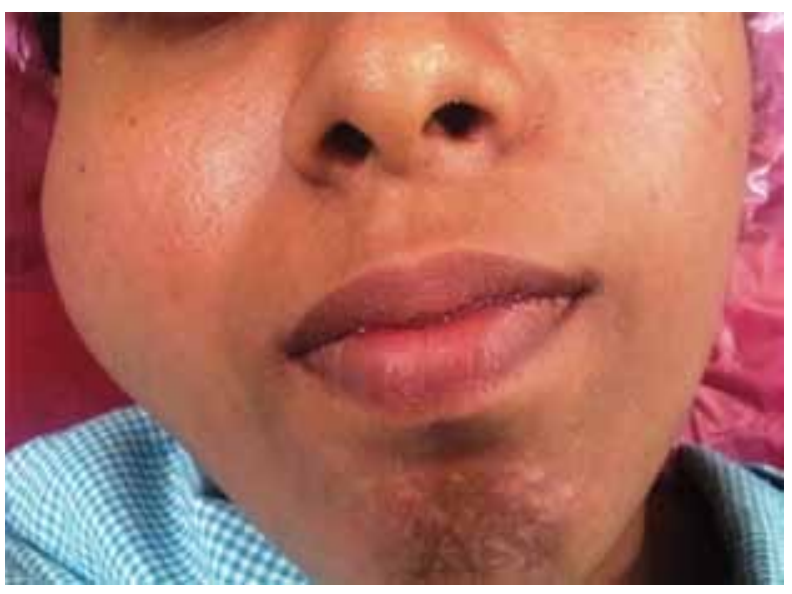

Fig. 1: Right side parotid swelling without any facial weakness 


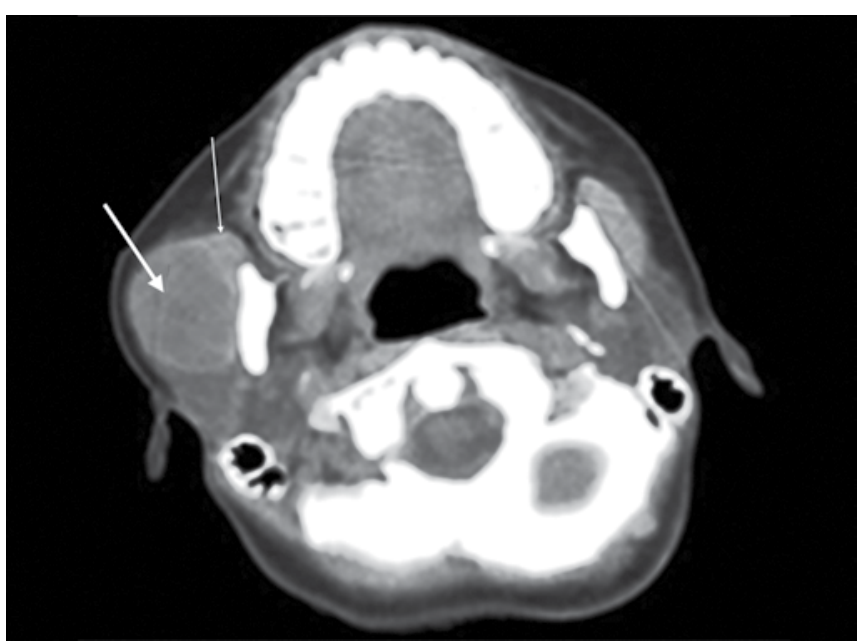

Fig. 2: Computed tomography scan of the neck: right side parotid mass (thick arrow) with preparotid lymph node (thin arrow) superficial to mandible

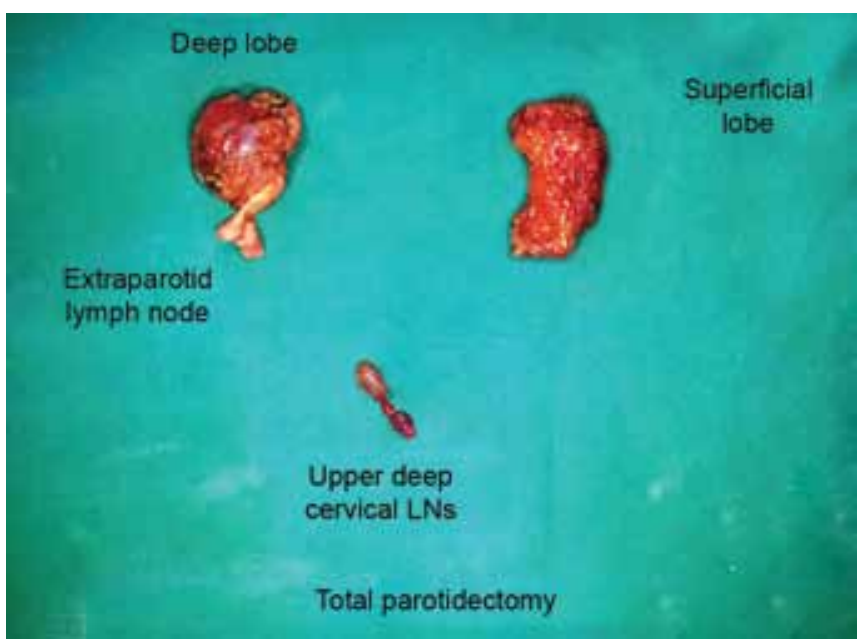

Fig. 4: Histopathology specimen (labeled)

\section{HISTOPATHOLOGY REPORT}

Deep lobe tumor features consistent with poorly differentiated malignancy (Fig. 5), superficial lobe found free of tumor; lymph nodes $2 / 2$ shows reactive changes.

Paraffin block sent for immunohistochemistry test to Apollo Hospital, Chennai, and Cancer Institute, Adyar. Both reports are shown in Tables attached respectively (Tables 1 and 2).

Further follow-up PET scan showed no metastasis except minimal right level II nodal uptake.

Molecular study was performed for SYT-SSX1 and SYT-SSX2, which came negative ruling out synovial sarcoma, while it is $100 \%$ sensitive for biphasic and $96 \%$ for monophasic synovial sarcoma. ${ }^{3}$

\section{ADJUVANT THERAPY}

In perspective of malignancy and with decision of tumor board, it considered as synovial sarcoma; hence, postoperative radiotherapy was given. Patient was followed

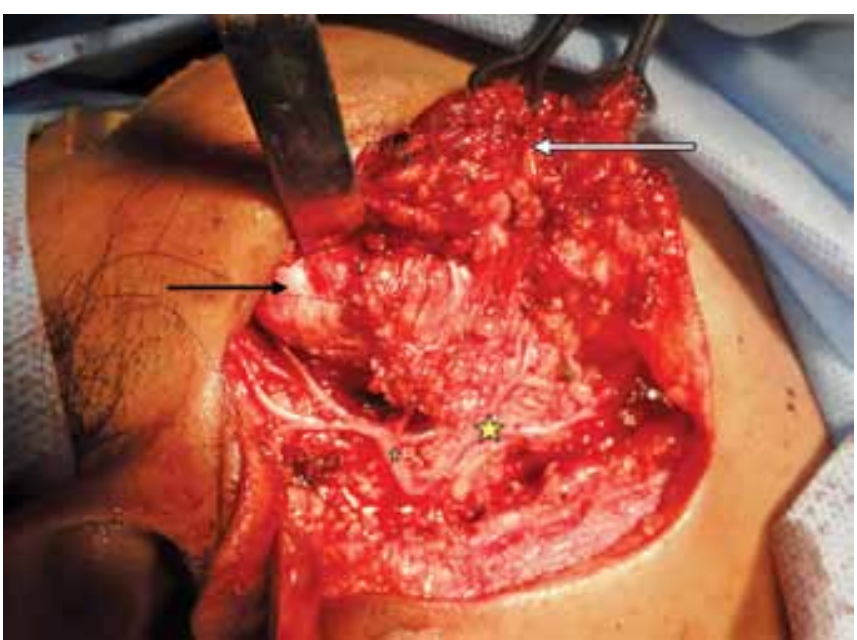

Fig. 3: Tumor under the neurovascular plane (black arrow), free superficial lobe (white arrow), *facial nerve division

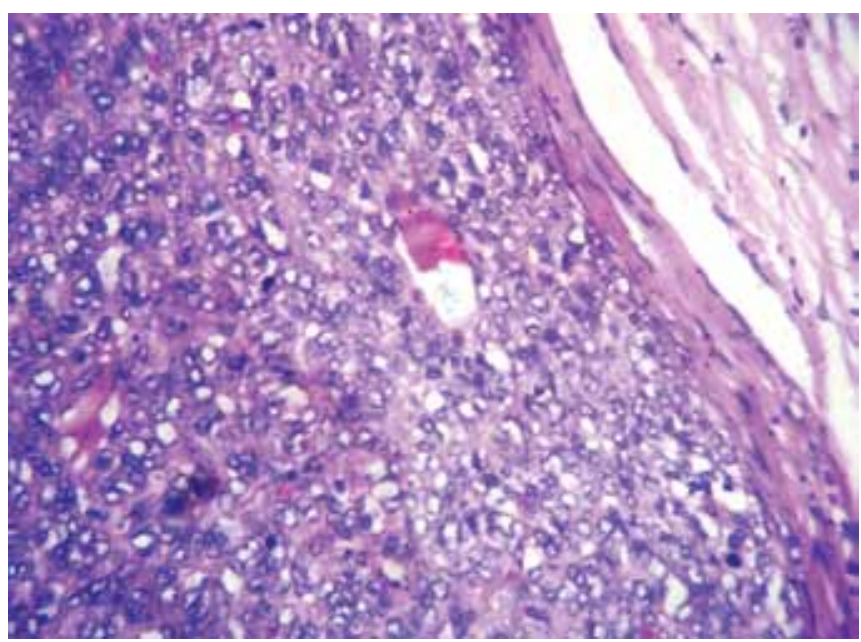

Fig. 5: High power histopathology slide showing no specific cell type with cellular atypia

up till the case report submitted with duration of 10 months. There is no recurrence in follow-up till now. Patient is healthy and doing well.

Table 1: Immunohistochemistry report: Apollo Hospital, Chennai

\begin{tabular}{lll}
\hline Positive (+) & Negative (-) & $+/$ \\
\hline Vimentin & Cytokeratin & CD5 \\
S-100 & SMA & CD9 \\
& CEA & \\
& Desmin & \\
& Synaptophysin & \\
& HMB 45 & \\
& Melan-A & \\
& CAM 5.2 & \\
& HMWK & \\
& P63 & \\
& CD10, CD34 \\
& LCA & \\
\end{tabular}

Impression: Malignant round cell tumor

- PNET

- Extraskeletal myxoid chondrosarcoma. Suggestion of molecular study. 
Table 2: Immunohistochemistry report: Cancer Institute, Adyar, Chennai

\begin{tabular}{ll}
\hline Positive (+) & Repeated days \\
\hline Vimentin & 1st day \\
Colponin & \\
EMA & 2nd day \\
S-100 & \\
Ki-67 & 3rd day \\
BCL-2 & \\
CD99_few cells shown partial membrane & \\
positive reaction & \\
\hline Impression: Sarcoma high grade_poorly differentiated sarcoma \\
is possibility. \\
$\begin{array}{l}\text { - Advised molecular genetic study for SYT-SSX translocation } \\
\text { CONCLUSION }\end{array}$
\end{tabular}

Diagnosis of synovial sarcoma on less common sites is diagnostic challenge. FNAC as benign is not reliable pre- operative investigation. Only final histopathology can give a clue of diagnosis and help in further management. Molecular study is hallmark standard of investigation in such cases, where diagnosis is great dilemma.

\section{REFERENCES}

1. Shmookler BM, Enzinger FM, Brannon RB. Orofacial synovial sarcoma: a clinicopathologic study of 11 new cases and review of the literature. Cancer 1982 Jul;50(2): 269-276.

2. Rigante M, Visocchi M, Petrone G, Mulè A, Bussu F. Synovial sarcoma of the parotid gland:a case report and review of the literature: ACTA Otorhinolaryngologica Italica 2011;31(1): 43-46.

3. DeVita VT Jr, Lawrence TS, Rosenberg SA. Devita's cancer principal and practice of oncology. 8th ed. Philadelphia, USA: Lippincott Williams \& Wilkins; 2009 Apr. 